\title{
Social Networks and Subjective Wellbeing: A Comparison of Australia, Britain, and China
}

DOI:

10.1007/s10902-017-9926-2

\section{Document Version}

Accepted author manuscript

Link to publication record in Manchester Research Explorer

\section{Citation for published version (APA):}

Bian, Y., Li, Y., \& Hao, M. (2017). Social Networks and Subjective Wellbeing: A Comparison of Australia, Britain, and China. Journal of Happiness Studies. https://doi.org/10.1007/s10902-017-9926-2

\section{Published in:}

Journal of Happiness Studies

\section{Citing this paper}

Please note that where the full-text provided on Manchester Research Explorer is the Author Accepted Manuscript or Proof version this may differ from the final Published version. If citing, it is advised that you check and use the publisher's definitive version.

\section{General rights}

Copyright and moral rights for the publications made accessible in the Research Explorer are retained by the authors and/or other copyright owners and it is a condition of accessing publications that users recognise and abide by the legal requirements associated with these rights.

\section{Takedown policy}

If you believe that this document breaches copyright please refer to the University of Manchester's Takedown Procedures [http://man.ac.uk/04Y6Bo] or contact uml.scholarlycommunications@manchester.ac.uk providing relevant details, so we can investigate your claim.

\section{OPEN ACCESS}




\section{Journal of Happiness Studies \\ Social Networks and Subjective Wellbeing: A Comparison of Australia, Britain, and China \\ --Manuscript Draft--}

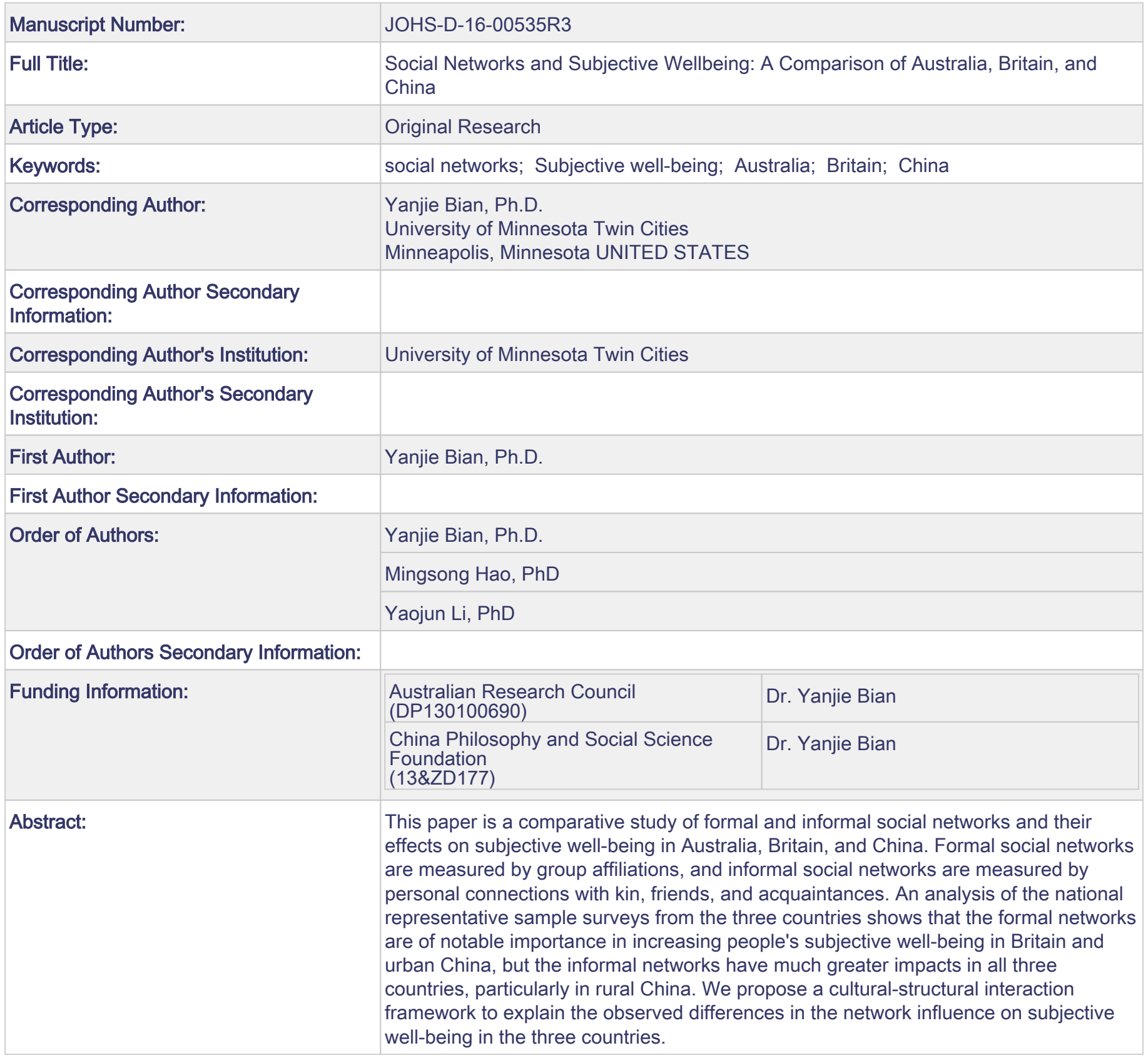




\section{Response to Comments from $2^{\text {nd }}$ Round of Review}

Manuscript No.: JOHS-D-16-00535R2

Title: Social Networks and Subjective Well-being: A Comparison of Australia, Britain, and China

Journal of Happiness Studies

Dear Editor and Associate Editor (AE):

Once again, we very much appreciate the comments from the second round of review. Consequently, we've taken time carefully studying these comments and tried our best to address the issues raised by AE and Reviewer 1. We also have thoroughly gone through the manuscript, making some minor changes and small edits in order to improve the exposition.

In this file, we describe the changes made in the submitted revision. Please note that for your convenience we've highlighted the substantive changes in light blue color.

\section{$\underline{\text { To Associate Editor }}$}

1. Difference in SWB scales. "It doesn't address the point that for Australia there is no "middle" response category. ... you might deal with this issue by expanding a bit in the first paragraph of your "limitations" section."

We highly appreciate AE's detailed comments, his point that without comparable datasets this issue can't be solved statistically, and his specific suggestion that we deal with it in the "limitations" section.

In the revised manuscript, we've dealt with this issue in two places. First, on p15, we add a new Footnote 1, in which we detail the rationale for our procedure to standardize the SWB scales for this study. Second, on pp. 26-27, in the first paragraph of the "limitations" section, we admit that because of the potential problem of incomparability of the SWB scales from the three countries under study, our analysis is best seen as an initial point of comparison for future researchers. We copy this revision for AE's convenience:

On SWB scales, for example, Australia has a 4-point scale without a middle, neutral, category for "neither happy nor unhappy", China's 5-point scale includes a middle category of "so-so" with nearly half of the respondents choosing it (45\% in the urban sample and $46 \%$ in the rural sample), and Britain has a more elaborated 10-point scale from "extremely unhappy to extremely happy" with the two middle categories chosen by around $15 \%$ of the respondents. Formal and informal networks, on the other hand, have different kinds of contents in the measurement devices across the three countries. Though we use the standardized scores of these variables, with 
theoretically-guided and rigorously-conducted models, it would be preferable to have instruments designed in the same way for cross-societal analysis. To be sure, this study sets up an initial point of comparison for future researchers.

2. Theoretical discussions. "Some of the other issues (raised by Reviewer\#1) might also be addressed that way ... revisions to the theory and discussion sections are in order to respond to the reviewer's concerns."

We've taken this suggestion from AE by addressing all of the concerns raised by Reviewer \#1. Please see our specific responses to R1.

\section{$\underline{\text { To Reviewer \#1 }}$}

We very much appreciate R1's both general and specific comments, which point to the connection between theory and analysis as well as the incomparability of SWB scales across the three countries under study. In his/her commentary, R1 made specific suggestions on how we should deal with these issues. Below we describe the specific changes made in the revised manuscript.

1. Measurement of formal networks. "Membership of sport and political organisations is frequent in urban China and I wonder how these specific types of organisation fit it. Are these under the jurisdiction of government offices as per the discussion?"

On p. 16, we now provide a detailed description of what we did to measure the five group memberships in the three countries. Two particular notes are used to interpret the high frequencies of participation in the two groups of "sport" and "political" memberships and activities. We copy this description below for R1's convenience:

In the original dataset, Australia uses a list of five group memberships, Britain twelve, and China seven. While these group memberships vary in types across the three countries, we use Australia's five groups as the basis and choose the same or similar groups (and drop the other groups) for Britain and China, as shown in Panel B of Table 2. A note of clarification is needed here on two groups. First, the group for "sports" includes various kinds of group sport activities, and in Chinese cities these include the highly popular and low-cost group activities such as martial arts, table tennis, group dance, and pushing-kicking exercises in public spaces such as parks, streets, and neighbourhoods, generating a high rate of participation in urban China. Second, the group for "political/voluntary" is a combination of two separate groups: "political" organisations in Australia and Britain, and "voluntary" organisations for China. Political participation in Australia and Britain are highly voluntary, a reason why we put voluntary group activities in this same category. China's original dataset does not have a "political" category for group activities. 
2. Differences between Chinese and Western networks. "You cite Burt and Burzynska on the level of interaction frequency and trust among strong ties, but how were ties classified in this study if not by trust/ interaction?"

Our previous description of Burt and Burzynska's study was imprecise and confusing, which led to R1's concern. We have changed our description in the revised manuscript, on p. 7. The revised description now points to the quantitative difference in the high presentation of strong ties among Chinese entrepreneurial networks and low presentation of strong ties in Western entrepreneurial networks. We copy this revision below for R1's convenience:

A recent study shows that while two thirds of Chinese entrepreneurs rely on strong ties to conduct businesses, especially at the founding and immediately subsequent years, only one in ten of American and European entrepreneurs do so (Burt and Burzynska 2017). This particular finding has been discussed with attention to the comparative significance of guanxi across the globe (Bian 2017).

\section{3. "The section on 'low context communication' is not particularly convincing."}

We have re-read the relevant statement of Hall (1959) cited on p. 12. This re-reading confirms that in his statement about low context communication Hall had a specific reference to American culture, but he interpreted this as being due to the European cultural roots in Britain and Germany. We therefore have felt it confident that we use this generalization of Hall's to highlight the key difference between Eastern relational culture and Western rational culture.

We admit that this is a weak point of our paper. We know more about relational culture in the East than rational culture in the West. Nonetheless, we need some references to back us in describing the differences in social networks between Chinese and Westerners, and we've used Hall, along with a few others (DiTomaso, Kipnis, ...), in this particular section. We've made no changes here.

4. "You cite Pichler and Wallace on class rigidity and social capital, but their country-level analysis, I believe, relates to income inequality not social mobility. I think that China may have income inequality that is higher than Britain or Australia, a point that may counter your argument/ hypothesis."

We thank the reviewer for pointing this out. We re-read the paper by Pichler and Wallace, and agree that in their analysis the focus was on class effects on civic engagement, rather than on cross-country differences in rigidity. The paper was thus of little relevance to the discussion we were making and we decided to drop the reference. 
5. Interpretative accuracy. "In the discussion section it is still stated: ...social networks more effects in rural and urban China whereas... formal social networks more effective in Australia and Britain."

Our previous statement as shown above was about our hypotheses, rather than findings. But in the conclusion, this statement is confusing. In the revision, on p. 26, we have focused on the findings and make reflections on these findings and how they support and do not support our hypotheses. We copy this particulate part below for R1's convenience:

Here the findings do not fully support our hypotheses. One hypothesis is that a stronger relational culture generates greater effects of informal networks on people's SWB in rural and urban China than in Australia and Britain, and this hypothesis has been fully supported. Another hypothesis is that a stronger rational culture generates greater effects of formal networks on people's SWB in Australia and Britain than in rural and urban China, but this hypothesis is not supported. The findings are that there is greater effect of formal networks on people's SWB in Britain and urban China than in Australia and rural China.

6. "You may wish to comment on the descriptives a little more; Australia has very high levels of civic engagement and I find myself wondering if the survey questions were comparable across the three sources."

A special thank-you is due to R1 for this suggestion. Indeed we did not do much to describe the descriptive results in the previous version. In the revision, on p. 16, we have elaborated on what we did to measure formal networks, emphasizing the groups that have differences across the three countries.

\section{To Reviewer \#2}

"The authors have dealt my all concerns. I think the paper is acceptable for publication with minor revisions. There were some errors of language expression which should be amended."

We are thankful to $\mathrm{R} 2$ for the positive reactions to our revision from the last round of review. This time we've gone through the manuscript thoroughly and make small edits in many places in order to increase the exposition. 


\section{Social Networks and Subjective Wellbeing:}

A Comparison of Australia, Britain, and China*

Yanjie Bian, IESSR, Xi'an Jiaotong University, Xi'an 710049, Shaanxi, China; and

Department of Sociology, University of Minnesota, 267 19th Ave South,

Minneapolis, MN 55455, USA. Email: yjbian@xjtu.edu.cn

Mingsong Hao, IESSR, Xi'an Jiaotong University, Xi'an 710049, Shaanxi, China.

Email: ms.hao@xjtu.edu.cn.

Yaojun Li, IESSR, Xi'an Jiaotong University, 710049, Shaanxi, China; and

University of Manchester, University of Manchester, UK. Email:

yaojun.li@manchester.uk

* Authorship is alphabetically arranged to honor equal contribution. Yanjie Bian is grateful to China's Philosophy and Social Science Foundation for a key-project grant (13\&ZD177), and Yanjie Bian and Yaojun Li are grateful to the Australian Research Council for a collaborative grant (DP130100690) with Mark Western and Xianbi Huang; both grants provided partial support for the research reported in this paper. The authors also wish to thank Xianbi Huang, Mark Western, Lei Zhang, Xiaowen Zhu, participants in a 2015 project symposium at University of Queensland, Brisbane, Australia, as well as the JOHS Editor Antonella Delle Fave, Associate Editor David Bartram, and anonymous reviewers for their helpful comments and suggestions on earlier drafts of this paper. 


\title{
Social Networks and Subjective Well-being:
}

A Comparison of Australia, Britain, and China

\begin{abstract}
This paper is a comparative study of formal and informal social networks and their effects on subjective well-being in Australia, Britain, and China. Formal social networks are measured by group affiliations, and informal social networks are measured by personal connections with kin, friends, and acquaintances. An analysis of the national representative sample surveys from the three countries shows that the formal networks are of notable importance in increasing people's subjective well-being in Britain and urban China, but the informal networks have much greater impacts in all three countries, particularly in rural China. We propose a cultural-structural interaction framework to explain the observed differences in the network influence on subjective well-being in the three countries.
\end{abstract}

Keywords: social networks; subjective well-being; Australia; Britain; China 
Social Networks and Subjective Well-being:

A Comparison of Australia, Britain, and China*

\begin{abstract}
This paper is a comparative study of formal and informal social networks and their effects on subjective well-being in Australia, Britain, and China. Formal social networks are measured by group affiliations, and informal social networks are measured by personal connections with kin, friends, and acquaintances. An analysis of the national representative sample surveys from the three countries shows that the formal networks are of notable importance in increasing people's subjective well-being in Britain and urban China, but the informal networks have much greater impacts in all three countries, particularly in rural China. We propose a cultural-structural interaction framework to explain the observed differences in the network influence on subjective well-being in the three countries.
\end{abstract}

Keywords: social networks; subjective well-being; Australia; Britain; China 


\section{Introduction}

Society is networked, and the well-connected are happier than others in Australia (Huang and Western 2015), Britain (Li 2007), China (Bian et al. 2014), and many other parts of the world (Helliwell and Putnam 2004; Song 2011). There are basically two explanations of the positive network influence on happiness or subjective well-being (SWB). First, well-connected persons obtain a good deal of emotional resources from others who generously give them the time and attention, share their feelings with due considerations, give advice with care, help resolve issues with actions and, more generally, provide them with needed social support which maintains one's SWB at a reasonably high level (House 2008). Second, well-connected persons also enjoy opportunities of access to instrumental resources, in forms of information, power, wealth, status and influence of significant others (Lin et al. 1981), and these "social resources" improve one's SWB both directly and indirectly (Lin 1982, 2001).

Of chief interest in this paper is the issue of how emotional and instrumental resources are made available from formal and informal channels of social networks and become effective for SWB. The formal channels refer to social groups, voluntary associations, and other nongovernment organizations (NGOs) whose membership ties are resourceful for emotional and instrumental purposes (Coleman 1990; Putnam 2000). The informal channels, on the other hand, are the personal ties that people develop with relatives, friends, and acquaintances (Granovetter 1973), and these ties are also resourceful for the same functions. To recognize their multifaceted relational roots and externalities, social network analysts have termed these two kinds of channels as 
"formal" and "informal" networks (Li et al. 2005; Bian and Hao 2013; Huang and Western 2015).

We argue that the relative importance of formal and informal networks in a given society is reflective of how that society is structured, and that the differences in the effects of formal and informal networks on SWB are a window into the structural constraints and opportunities people face in different societies. To what extent do formal and informal networks increase people's SWB in Australia, Britain, and China? What are the similarities and differences in formal and informal networks among the three countries? And how do formal and informal social networks exert their impacts on people's SWB across the three countries? Before presenting statistical results in relation to these questions, we provide a theoretical discussion to guide our empirical analysis.

\section{Formal and informal social networks}

\subsection{Basic ideas}

Social networks, formal or informal, are the basis from which social capital is generated to affect people's behaviors and perceptions, including SWB. While economic capital is external to social actors and human capital is internalized in them, social capital is embedded in and can be mobilized from the networks of ongoing relationships between social actors (Bourdieu 1986; Coleman 1990; Portes 1998; Lin 2001). The main functions of social capital are to bridge people across structural boundaries as well as bind them together within the communities to which they belong 
(Putnam 2000).

While social actors are embedded in the networks of ongoing relationships (Granovetter 1985), formal and informal networks are qualitatively different from each other ( $\mathrm{Li}$ et al. 2005). The formal networks are developed from individuals' membership ties with social groups, voluntary associations, and other NGOs. These are the ties through which individuals can engage in society at large (Putnam 2000). While such ties may transform one's personal worlds, the informal networks mostly develop from kin ties, pseudo-kin ties, friendships, and acquaintanceships (Granovetter 1973; Lin 1982, 2001; Bian 1997, 2010; Li, Heath and Devine 2015). Unlike membership ties in the formal networks, social ties in the informal networks are essentially personal.

The distinction between the formal and the informal networks has important implications for the kinds of social resources that are made available to individuals through them. The informal networks are full of dyads of private individuals who share personal emotions and particular feelings toward each other, and are enhanced and strengthened through the build-up of sentiments and obligations on the dyadic basis (Lin 2001; Bian 2001, 2010). The formal networks, on the other hand, tend to bind group members together through formal procedures, membership fees, or other kinds of rule-binding rituals, and operate through the exercise of rights and interest satisfactions on behalf of the members (Putnam 2000). Consequently, whereas informal networks are rich in emotional and practical resources in the form of understanding, caring, trust, and social and material support thus generating both instrumental and expressive kinds of support (Lin 2001), formal networks are a source of tangible (e.g., 
skills and assets) and intangible (e.g., information and status) institutionalized resources whose very nature is more instrumental than emotional (Li 2015). It is of course also the case that some of the ties established via formal civic engagement become personal ties and that personal ties thus constituted contribute to the further construction of formal memberships in civic organisations where the formal and the informal boundaries become blurred and mutually reinforcing (Putnam 2000).

\subsection{Informal networks in the East and the West}

In the East, Confucianism, China's main philosophy that has spread to Japan, Korea, Singapore, and other parts of East Asia, emphasizes and recognizes personal relationships, or guanxi in Chinese expression, as the core of the society. Guanxi is referred to as "a dyadic, particular, and sentimental tie that has the potential of facilitating favor exchange between the parties connected by the tie" (Bian 2006: 312). Guanxi is originated in familial ties of sentiment and obligation within kinship networks (Liang 1986[1949]; Fei 1992[1949]), but it goes beyond kinship boundaries to dictate social interactions in society at large through the norms of grace (or "face" in eastern culture, an expression which has also been gaining acceptance in western culture), favor, and reciprocity (Fried 1969[1953]; King 1985; Hwang 1987). Persons connected by a non-kin tie can develop guanxi between them if they repeatedly develop and strengthen family-like sentiments and, at the same time, build up obligations to each other, making the tie a pseudo-kin tie (Lin 2001; Bian 2001, 2010). The degree of particularism in both kin and pseudo-kin ties is fortified by the build-up of personalized obligations (renqing), face (mianzi), and emotional attachment (ganqing), which jointly impose 
relational constraints by exerting social-psychological pressure on favor granter and favor recipient alike (King 1985, 1991; Zhai 2009).

The significance of guanxi in Maoist China (1949-1976) was manifested in the socialist economy in which most people were faced with poverty and personal relationships were mobilized to break free bureaucratic controls over an array of economic resources, daily necessities, consumer goods, and public services (Whyte and Parish, 1984; Bian 1994; Yang 1994; Yan 1996; Kipnis 1997). In Maoist system of party clientelism and organized dependence, "instrumental-particular ties" with authorities were essential for day-to-day survival and politicized opportunities (Walder 1986). In post-Mao, reform-era, China, personal relationships have retained their significance for meandering through institutional uncertainties with heightened competitions and unleashed influences of political power in creating greater "social networking spaces" in economic, social, and political domains (Bian and Zhang 2014). The prevalence and the increasing significance of guanxi in China's transitional economy are widely observed and well documented (Bian and Huang 2015; Bian et al. 2015; Bian in press).

In the West, Durkheim's pioneering work on suicide presents a classical account of the importance of informal social networks for social cohesion and social integration (Durkheim 1951). But Durkheim also makes a theoretical distinction between "mechanic solidarity" for preindustrial society and "organic solidarity" for industrial society, pointing to the transformation from the traditional, homogenous, networks of similar persons to the modern interdependence of heterogeneous social roles and positions. Strong ties embedded within informal networks in advanced western 
countries continue to be important within communities (Gans 1982[1962]; Coleman 1990), but weak ties of infrequent interaction and low emotional attachment (Granovetter 1973) and strategic positions of "structural holes" (Burt 1992) allow nonredundant information and resources to flow across persons and groups that are otherwise disconnected from one another.

The afore-mentioned features of informal networks between the East and the West have led us to recognize a well-documented finding from comparative social network analysis, namely, that the concentration of weak ties in informal networks for westerners stands in some sharp contrast to that of strong ties for the Chinese (Bian 1997; Bian and Ang 1997; Huang and Western 2011; Chua 2011; Li 2013). A recent study shows that while two thirds of Chinese entrepreneurs rely on strong ties to conduct businesses, especially at the founding and immediately subsequent years, only one in ten of American and European entrepreneurs do so (Burt and Burzynska 2017). This particular finding has been discussed with attention to the comparative significance of guanxi across the globe (Bian 2017).

\subsection{Formal networks in the West and the East}

Formal networks as composed of individuals' membership ties with various social groups and NGOs are a strong source of social capital in advanced Western societies (Putnam 1995, 2000; Hall 1999; Li et al. 2003, 2005). Labour unions and religious institutions are two of the many examples. The truck drivers' association in the United States, for example, protects its members through contract negotiations and its strong influence on hiring and firing decisions (Lindbeck and Snower 1986; Dickens and Lang 
1988). Church members, on the other hand, develop strong identities and norms of sharing and mutual support (Pollner 1989; Emmons et al. 1998; Haslam et al. 2009). While association-based social capital may have been on the decline in the United States and Britain (Putnam 2000; Li et al. 2003), a recent study shows that the formal, membership-based networks still serve as stable structures which can cultivate personal ties and friendships (Lim and Putnam 2010). In Britain and Australia, while the impact of social class on social capital is an issue for scholarly debate (Hall 1999; Li et al. 2003), it is nevertheless the case that participation in formal civic life is helpful to people in a range of social life domains such as developing bridging ties (Muttarak 2014), enhancing health status and increasing one's SWB (Baum et al 2000; Bjørnskov 2003; Berry and Welsh 2010; Huang and Western 2011, 2015; Li 2007, 2016).

Formal networks exist in China but with Chinese characteristics. Maoist collectivism and bureaucratic control over resources and opportunities of access were operated through rural communes and urban work units (danwei) as distributive mechanisms, making work colleagues the most frequent source of "discussion networks" among the Chinese people in the 1980s (Ruan et al. 1987). While some of workplacebased relations transform into social ties on personal levels (Sun 1996; Zhang 2008) and generate instrumental social capital, post-Mao China has witnessed a growth of NGOs which are, in most instances, affiliated with and operative under the jurisdiction of government offices (Jin 2010). The appearance of autonomous, self-organizing NGOs in China is only a fairly recent phenomenon (Ji 2013).

The foregoing discussions suggest two main features about formal networks. First, 


\begin{abstract}
Australia and Britain have stronger third-sector organizations, otherwise known in the literature as non-profit and non-governmental organizations, than in China, and consequently formal networks may be more consequential for people's well-being in Australia and Britain than in China. Second, while both formal and informal social networks can generate emotional and instrumental resources, it is in the informal networks that one can more often find emotional resources than in the formal networks. When formal networks provide emotional resources, these resources are by and large generated from the informal networks of friendships that have grown from inside the formal networks and via co-participation in civic engagements.
\end{abstract}

\title{
3 The influence of social networks on SWB: hypotheses
}

\subsection{Factors influencing SWB}

SWB is people's cognitive and affective evaluation of their lives. One of the authorities on the topic, Diener (2000) provides both a comprehensive review and a multi-perspective framework for studying SWB. Following Diener, we consider SWB as a function of three sets of factors. The first set refers to personal characteristics, such as an individual's gender, age, health status, and behavioral habits (George and Landerman 1984; Dolan and White 2008; Anderson 2014). The second set concerns economic factors, including an individual's income as well as wealth and consumption as captured by one's social class position (Easterlin 1974; Diener and Diener 1995; Goldthorpe and McKnight 2006). The third set emphasizes social factors, including an individual's formal and informal networks (Baumeister and Leary 1995; Myers 2000; 
Bian et al. 2015). In this paper, we pay special attention to the third set of factors and analyze the effects of formal and informal networks on SWB among the three countries under study.

\subsection{Effects of formal and informal networks}

Previous research shows that occupational status, group affiliation, marital status, and personal attachments have significant influences on people's SWB (Baumeister and Leary 1995; Myers 2000; Putnam 2000; Thoits 2011; Richards 2016). Generally speaking, socially integrated individuals are happier than isolated ones simply because people feel their lives fulfilled when they are recognized, accepted, valued, and honored by the significant others surrounding them (Bian and Xiao 2014; Bian et al. 2015).

Those who are deeply embedded in formal and informal social networks, or "machers" and "schmoozers" as Putnam (2000) vividly calls them, tend to benefit from both the instrumental and the emotional sides of social resources. Such resources are engendered through interpersonal interactions in the activities. However, formal engagement is typically conducted in more or less institutionalized settings which, while fostering bridging ties, tend to lack the personal, particular, and emotional touch (Baumeister and Leary 1995). In contrast, interactions through informal social milieus are frequently personal and intimate, where expressions of sympathy, understanding, encouragement, appreciation, and other kinds of emotional support are conveyed, which are very important for reducing anxiety, ensuring peace of mind, and enhancing happiness (Jamieson 1998; Myers 2000; Diener 2000; Pahl 2000).

In sum, social networks will tend to have a positive impact on people's SWB 
independent of their demographic attributes or socio-economic positions. Based on the theoretical discussions and existing empirical findings, we now formulate the first hypothesis as follows:

Hypothesis 1: While both formal and informal networks are expected to have positive effects on SWB, the effect of the informal is stronger than that of the formal in Australia, Britain, and China.

\subsection{A cultural-structural interactive model and the derived hypotheses}

The extent to which social networks affect people's SWB potentially varies across the social and cultural contexts of Australia, Britain, and China. Theoretically, we argue that two contextual dimensions enhance or suppress network effects: the degree of relationalism in a culture, and the rigidity of social closure that shapes social interactions in a society.

Relationalism refers to the legitimacy of the emotional and instrumental values of social relationships. China exemplifies a strong and persistent relational culture in which social relationships are widely valued (Bian and Huang 2015), and collectivism and interdependence are emphasized over individualism and independence (Gold et al. 2002; DiTomaso and Bian 2016). Australia and Britain, on the other hand, represent strong rationality-oriented cultures in which individuals' interests and values assume greater primacy. Rational culture normalizes what is called low context communication (Hall 1959), where it is assumed that understanding comes only by saying explicitly what one wants the other person to know. In contrast, communication within relational culture is high context, in which there is a great deal of understanding without the use 
of words because people know a lot about others by knowing the context of their relationships (Kipnis 1997). Consequently, strong and widespread relational understandings contribute to shared expectations that linked actors will behave in a predictable and normative way. Therefore, we expect the informal social networks to exert greater impacts on SWB in China than in Australia or Britain. In the case of China, we would also wish to differentiate between rural and urban sectors. In rural China, strong ties among kin, relatives and neighbors may prevail owing to the relative lack of socioeconomic development, whereas in urban China greater weak ties with colleagues, acquaintances, and school friends as well as ties obtained from civic activities may assume a greater role in affecting people's socioeconomic lives.

The rigidity of social closure refers to the extent to which boundaries to social interaction remain fluid or closed. While there is an ongoing debate as to whether British society is getting more rigid (Blanden et al. 2005) or more open (Li and Devine 2011, 2014; Devine and Li 2013; Li and Heath 2016) or has witnessed no significant change in social fluidity over the last few decades (Goldthorpe and Mills 2008), there is some consensus that class rigidity is related to civic engagement ( $\mathrm{Li}$ et al. 2005; $\mathrm{Li}$ and Marsh 2008). Furthermore, research also shows that Australia is more open than Britain in having higher levels of (absolute) social mobility (Erikson and Goldthorpe 1992: 331; Western 1994) and weaker barriers to the formation of friendship and marriage ties (Western 1991; Li 2002). Both countries were founded by the same 'charter population' as Heath and Cheung (2007: 1) termed it and have basically similar socioeconomic institutions and civic organizations. However, differences in social 
rigidity may have different impacts on formal and informal social engagement which may, in turn, have different effects on people's SWB in the two countries. Our analysis will thus shed light on cultural-structural influences of social networks on SWB both between the two capitalist countries and between them and China, a state socialist country. Weak social boundaries are associated with more heterogeneous social relationships (Blau and Schwartz 1984), providing access to more diverse resources in social networks. We would thus expect network effects on SWB to be enhanced in less rigid societies such as Australia as compared with Britain or China.

These considerations suggest a four-way ideal-typical conceptual model. The first ideal type has a weak relational culture and a low social closure as would be exemplified by Australia. The second ideal type has a weak relational culture and a stronger social closure as represented by Britain. The third ideal type has a strong relational culture and a high social closure as prevalent in rural China. And finally, the fourth ideal type has a strong relational culture and a low social closure as is taking shape in urban China which is undergoing rapid economic and social changes.

This model has guided China-Britain comparisons (Bian and Hao 2013; Bian and Xiao 2014; Li, Zhang and Kong 2015). It has been found that informal networks have a much stronger effect on SWB in China than in Britain (Bian and Xiao 2014), although Britain has much stronger formal networks than does China (Bian and Hao 2013). Based on these earlier findings, we propose two more hypotheses as follows:

Hypothesis 2: The influence of informal networks on SWB is stronger in rural and urban China than in Australia and Britain. 
Hypothesis 3: The influence of formal networks on SWB is stronger in Britain and Australia than in urban and rural China.

\section{Research design}

\subsection{Data}

While comparable data are hard to come by for cross-national analysis, we find a suitable dataset from each of the three countries under study. For Australia, we use the Australian Survey of Social Attitudes (AuSSA2007), which is a nationally representative sample with 2,310 respondents aged 18-69, an age range we then impose for all three countries. The British data come from the 2008-2009 Taking Part Survey (TPS2008-09) with a valid sample size of 11,531 respondents residing in England. For China, the 2005 Chinese General Social Survey (CGSS) is used, with a valid sample size of 9,696 which is divided into rural $(4,366)$ and urban $(5,330)$ subsamples. These samples allow us to analyse "four societies": Australia, Britain, urban China, and rural China.

\subsection{Variables}

(1) Subjective well-being (SWB). In Table 1, we show the country-specific distributions of SWB (left panel). Each country measures SWB with a different scale and a somewhat different wording. Australia uses a 4-point scale (from "not at all happy" to "very happy"), Britain a 10-point scale (from "extremely unhappy" to "extremely happy"), and China a 5-point scale (from "very unhappy" to "very happy"). ${ }^{1}$ Using the

${ }^{1}$ The different number of categories between Australia and Britain may, at first sight, 
proportional-adjustment method (Colman et al. 1997) to standardize the scales, we adjusted the original values in the British $\left(\mathrm{Y}_{\text {adj. }}=\mathrm{Y}_{\text {ori. }} \mathrm{X} 4 / 10\right)$ and the Chinese $\left(\mathrm{Y}_{\text {adj. }}=\mathrm{Y}_{\text {ori. }}\right.$ $x$ 4/5) data by the values in the Australian data. The distributions of adjusted values and their means and standard deviations are presented in the right panel of Table 1 . The country differences in SWB are statistically significant from each other, as shown in pairwise t-tests presented in the lower section of the right panel. On average, Australians are the happiest, with the British being happier than Chinese urbanites, and rural Chinese people having the lowest SWB scores.

\section{(Table 1 about here)}

(2) Informal networks. One measure that is available from the three datasets we use in this study is the frequency of contact with relatives and friends, as shown in Panel A of Table 2. This measurement device meets our analytic purpose because, as shown by Marsden and Campbell (1984), the higher the frequency of contact with relative and

\footnotetext{
suggest some serious difficulties for the analysis, with the former having four and the latter ten categories. However, on closer scrutiny, the problem is not particularly severe. If we were to re-code the British data into a four-category variable, then the responses in the current $5^{\text {th }}$ category would go up and those in the $6^{\text {th }}$ category would go down, resulting in $1.1 \%, 10.8 \%, 54.5 \%$ and $33.6 \%$ respectively, a pattern very similar to that found for Australia. Given this and our standardization procedure, we would believe that the approach we have taken is a reasonable one in the absence of strictly comparable data. We thank the Associated Editor and one of the Reviewers for alerting the issue to us.
} 
friends, the more emotional resources there are from the informal networks ${ }^{2}$.

(Table 2 about here)

(3) Formal networks. These measures are based on group memberships and activities. In the original dataset, Australia uses a list of five group memberships, Britain twelve, and China seven. While these group memberships vary in types across the three countries, we use Australia's five groups as the basis and choose the same or similar groups (and drop the other groups) for Britain and China, as shown in Panel B of Table 2. A note of clarification is needed here on two groups. First, the group for "sports" includes various kinds of group sport activities, and in Chinese cities these include the highly popular and low-cost group activities such as martial arts, table tennis, group dance, and pushing-kicking exercises in public spaces such as parks, streets, and neighbourhoods, generating a high rate of participation in urban China. Second, the group for "political/voluntary" is a combination of two separate groups: "political" organisations in Australia and Britain, and "voluntary" organisations for China. Political participation in Australia and Britain are highly voluntary, a reason why we put voluntary group activities in this same category. China's original dataset does not have a "political" category for group activities. Nonetheless, Table 2 shows that the three countries vary a great deal in terms of participation in group activities, with Australia being the highest and rural China the lowest.

\footnotetext{
2 Australian and British datasets separate relatives from friends but the Chinese dataset combines the two. To make them comparable with each other, we combine relatives and friends in the Australian and British datasets.
} 
${ }^{3}$ In our case, the set of variables for formal social networks meets the criteria better than does that for informal networks but for consistency, we use the IRT modeling in both formal and informal domains. Under the IRT, a single continuous factor is posited to underlie responses to items within a set but this factor is 'measured' subject to error by each item. A continuous score thus underlies each item, the sum of a true score contribution and an error. The distribution of this score is divided up by a set of ordered thresholds, with each section of the distribution being associated with observing one of the possible ordered categorical responses. A respondent's categorical score is therefore determined by their continuous score falling within a particular range of values defined by an adjacent pair of thresholds. Since the continuous score is not directly observable, it is commonly considered to be a latent variable.

As different items may have different characteristics, they are allowed to differ in two ways. Firstly, items may have different threshold parameters. This allows, for example, fewer people to have memberships in political organizations than in sports clubs in Britain or Australia. Secondly, items may have different loading parameters. This allows items to be strongly or weakly related to the underlying factor, or correspondingly to vary in the extent to which they measure the underlying factor rather than something else. Choosing a proportional odds ordinal logistic parameterization allows the model to be specified by 
(4) Variables of Individual Attributes. People's SWB is affected by a number of socio-demographic attributes (Easterlin1974; George and Landerman1984; Diener 2000; Dolan and White 2008; Anderson 2014; Li 2016; Zhao et al. 2017), and these personal attributes must be controlled for in statistical models to assess the net effects of formal and informal networks on SWB. In our analysis, we include gender, age, health status, marital status, education, occupation, and income. ${ }^{4}$ Descriptive statistics

$\ln \left(\operatorname{pr}\left(Y_{i j}<=k\right) / \operatorname{pr}\left(Y_{i j}>k\right)\right)=\alpha_{i K}+\lambda_{i} \eta_{j}$

where $Y_{i j}$ is the response to item $\mathrm{i}$ from individual $\mathrm{j}, \eta_{j}$ is the score of individual $\mathrm{j}$ on the latent factor, $\lambda_{i}$ is the factor loading for item i, $\alpha_{i K}$ is the threshold for a response of $\mathrm{K}$ or above. For an item with $\mathrm{K}$ categories, 1 to $\mathrm{K}, \alpha_{i K}=\infty$. It is also usual to make some parametric assumption about the distribution of the latent variable in the population. We have assumed this to be normally distributed. The models were estimated by maximum likelihood in STATA using gllamm (Generalized Linear Latent and Mixed Models) (Rabe-Hesketh and Skrondal 2012). The details of IRT loadings are available on request and we show the minimum and maximum scores obtained via the Expected A Posteriori (EAP) method (Zheng and Rabe-Hesketh 2007) in Table 2. ${ }_{4}$ There are sizeable missing data on education in the British sample: $18 \%$ were excluded from the analysis as they had not completed full-time education yet and $3.4 \%$ had 'unknown' levels of education. The missing cases in Australia and urban and rural China are minimal, all within $1.0 \%$. There are also missing cases on class in the range of 3.0\%-9.3\% for the four societies. Following Greenland and Finkle (1995), we omitted the missing cases in the analysis. Including the missing as dummy variables does not have any substantial change on the effects of formal and informal social networks on subjective well-being in the four societies. We also conducted a separate analysis using ordinal logit (ologit) regressions and the pattern is essentially the same as shown in Table 3, with informal social networks having significant and positive 
of these variables are presented in Panel C of Table 2.

\subsection{Analytic strategy}

We test our hypotheses in two steps. First, we use the average marginal effects (AME) models to assess the effects of formal and informal social networks on SWB for each society separately, and the statistical results are presented in Table $3^{5}$. As the AME coefficients represent percentage-point differences, the levels of SWB and the effect sizes of its determinants can be directly compared across the four societies, allowing us to test the hypotheses in a meaningful and yet intuitive way. Second, we pool the four samples together and run the AME models with society-network interactions. The estimates of these interaction terms, presented in Table 4, allow for a direct test of crosssociety differences with regard to the effects of social networks on SWB. In both Tables 3 and 4, the standardized EAP scores are used for measuring informal and formal networks in order to compare the magnitudes of their effects.

\section{Results}

\subsection{Results from country-specific models}

Table 3 shows that informal networks have stronger effects than do formal

\footnotetext{
effects for all four societies and formal networks being positively and significantly associated with SWB for only Britain and urban China (full details of ologit models are available upon request).

5 The AME models are based on OLS regressions. We used the eydx option on the margins command in STATA to turn the coefficients into elasticities. The elasticities represent proportional changes in the dependent variable for unit changes in independent variables.
} 
networks in all four societies. In each of the four societies, informal social networks are significantly associated with SWB, net of the effects of all other covariates controlled for in the models. The formal networks, however, are significant in only Britain and urban China. Holding constant all other factors in the models, informal social networks' effects on SWB are most salient in rural China. An increase of one standard deviation in informal social networks is associated with an increase in happiness by 4.6 (a coefficient of 0.046) percentage points for rural Chinese people, and the corresponding increase for Britons is only 1.9 (a coefficient of 0.019) percentage points. Further tests also show that the effects of informal social networks are significantly larger than those of formal ones in each of the four societies (at the 0.01 level or higher). These results lend strong support for Hypothesis 1.

\section{(Table 3 about here)}

The effects of personal attributes are worth noting. In keeping with previous studies, women are happier than men; the curvilinear shape of age effects suggests that younger and older persons are happier than middle-aged persons, who are "sandwiched" by the dual obligations to take care of young children and ageing parents; and healthier people and the married are also happier. All these features are consistently observed across the four societies.

The effects of education, income, and occupation vary across the four societies. With the other factors controlled for in the models, higher levels of education are positively related with SWB in Britain and urban China, but not in Australia or rural China. Income does not have significant net effects on SWB in Australia, although it 
makes a positive impact on SWB in the other three societies. The class effects in Australia and Britain are very weak, suggesting a close association between education, class, and income in the two countries. The stronger demographic and weaker socioeconomic effects in Australia than in Britain suggest that the former is a more fluid society than the latter. Our previous discussion has indicated this from the perspective of social mobility research and we here find evidence on SWB. As a developing country, China has a much smaller professional-managerial salariat than Britain (Li, Zhang and Kong 2015) and even for people with the same amounts of income, those situated in salariat positions tend to feel more fulfilled than their counterparts who nevertheless occupy lower social positions.

\subsection{Results from society-interactive models}

We have, in the above, shown that informal social networks have significantly stronger net effects than do formal networks on people's SWB in all four societies. This leaves the question of whether informal, or formal, networks' effects are stronger in one country than in another. For this purpose, we conducted a cross-society analysis based on the pooled data of the four society-samples, with rural China as the reference category.

Table 4 shows the results of the cross-country analysis with three models. Model 1 is the base-line model, which estimates the independent effects of society as well as formal and informal social networks on SWB. Model 2 is the main interaction model, with both formal and informal networks interacting with societies. Model 3 is the full model where socio-demographic attributes are added as control variables; for ease of 
presentation and exposition, the coefficients of the control variables are not presented (but available upon request).

(Table 4 about here)

A closer scrutiny of Table 4 reveals four patterns. Firstly, as seen under Model 1, the general level of SWB varies among the four societies, in the order of Australia, Britain, urban China, and rural China (the reference society). These coefficients are statistically significant and confirm the findings from Table 1. Specifically, holding constant the effects of formal and informal social networks, Australians, Britons, and urban Chinese are happier than the rural Chinese by significant margins of 17.2, 14.5, and 2.3 percentage points, respectively.

Secondly, and still referring to Model 1 and net of society-specific differences, we find that both informal networks and formal networks exert significant effects on people's SWB, with the effects of informal social networks being over twice the size as those for the formal networks (a standard-deviation change in the two networks is associated with an increase in SWB by 3.8 and 1.5 percentage points, respectively). Further analysis again shows that this represents a statistically significant difference at the 0.001 level (the $\chi^{2}$ is 76.57 with 1 degree of freedom). The findings here again render strong support for Hypothesis 1.

Thirdly, moving to Model 2 with regard to between-society effects of formal and informal network on SWB, we find some differences in the expected directions. Looking firstly at the results for informal social networks, we find that, while Australians and Britons are happier than rural Chinese people at the overall level as 
shown in the main effects, informal networks make a significantly smaller contribution to their SWB than in the case of the rural Chinese, by 1.9 and 3.3 percentage points whereas there is little difference between urban and rural residents within China. This provides clear support to Hypothesis 2. Turning next to results on formal networks, we find that, formal networks make a significant, albeit small, contribution to SWB (by 0.8 and 1.1 percentage points relative to the rural Chinese). These findings render partial support for Hypothesis 3.

There are marked differences in socioeconomic conditions across the four societies, with rural Chinese having much lower levels of education, occupation, and income. The question that ensues from this is how the society-specific social network effects would manifest themselves once the variations in socioeconomic factors are taken into account. This is shown in the full interaction effects model. Thus, our final important finding from Table 4 is that, other things being equal, people in Australia and Britain are no different from rural Chinese people in terms of SWB and that there is no difference in the impacts of formal social networks on SWB among any of the four societies covered in our analysis. Yet, importantly, we find that informal social networks still retain their net significance but they make a significantly smaller contribution to British people's SWB than to the rural Chinese by 2.2 percentage points, a finding that may well reflect the highly entwined social networks among the rural Chinese. As a highly developed society, high levels of social, and concomitant geographic, mobility in Britain would make it harder to foster such thick networks. Piecing these findings together, our analysis suggests that the impacts of formal social networks are driven 
primarily by differences in socioeconomic conditions while those of informal social networks are much less affected by such differences.

\section{Conclusion and limitations}

\subsection{Conclusion}

Previous studies have shown that well-connected individuals are happier than the less-connected. In this paper, we differentiated between formal networks established from people's memberships of and participation in formal civic organizations, and informal networks developed from personal ties with relatives, friends, colleagues, and acquaintances. This differentiation combined with other innovations in our analysis has enabled us to analyze the formal and the informal social networks' effects on subjective well-being among Australia, Britain, and urban and rural China, enhancing our understanding about the positive effects of social networks on people's SWB. Our analysis leads to the following four conclusions.

First, our analysis has for the first time in comparative empirical research demonstrated that Australians are happier than Britons, who are in turn happier than Chinese urbanites, leaving the rural Chinese as the least happy on a comparable scale of happiness. This holds true even after their social network characteristics are held constant. Although this finding is open to more nuanced interpretations, it is important to establish this pattern of empirical evidence before further research effort is made to explore the causes of these four-fold differences in happiness.

Second, individual-level variations among the societies are an important source of 
theoretical explanation for the cross-societal differences in happiness. Our analysis shows that Australians and Britons are happier than the Chinese urbanites and peasants largely because they either have happiness-inducing factors, such as higher occupational positions and higher incomes, or higher happiness generators such as enhanced health status. Whether or not these individual-level variations do indeed produce the above-described patterns about the cross-country differences in SWB awaits further scrutiny. In this regard, we need to note that different levels of socioeconomic development could also make a significant contribution to differences in SWB. Australia and Britain are highly developed societies with well-developed welfare policies such as unemployment protection and pension schemes and pro-health infrastructures mitigating the negative consequences of poor health and other repercussions of socio-economic life whereas in China, particular in the rural sector, welfare schemes and health-care facilities are much poorer.

Third, with a theoretical innovation to differentiate between formal and informal social networks, we were able to establish an understanding that both types of these social networks increase people's SWB in Australia, Britain, urban China, and rural China, despite the fact that these societies are structurally and culturally different from each other. Because emotional resources are of greater importance to people's SWB than are instrumental resources, and since the informal social networks are a stronger and more durable supplier of emotional resources, we have hypothesized that informal social networks maintain and increase people's SWB with a stronger effectiveness than do formal social networks, and this should be true in all societies. This hypothesis has 
been consistently supported by our analysis on the four societies. Therefore, of fundamental importance for one's happiness is to live or work in a social milieu where one could frequently and intimately socialize with kin, friends, neighbors and colleagues.

Fourth, the society-interactive models have allowed us to produce findings on the differential effects of formal and informal social networks across the four societies. Here the findings do not fully support our hypotheses. One hypothesis is that a stronger relational culture generates greater effects of informal networks on people's SWB in rural and urban China than in Australia and Britain, and this hypothesis has been fully supported. Another hypothesis is that a stronger rational culture generates greater effects of formal networks on people's SWB in Australia and Britain than in rural and urban China, but this hypothesis is not supported. The findings are that there is greater effect of formal networks on people's SWB in Britain and urban China than in Australia and rural China. These effects are subject to the variations in the population characteristics at the individual levels in the respective countries.

\subsection{Limitations}

Some of these conclusions await further investigation in future research. Our measurement devices of both SWB and two types of social networks are confined to the available data in the surveys at our disposal which are not specifically designed for cross-national analyses. On SWB scales, for example, Australia has a 4-point scale without a middle, neutral, category for "neither happy nor unhappy", China's 5-point scale includes a middle category of "so-so" with nearly half of the respondents choosing 
it (45\% in the urban sample and $46 \%$ in the rural sample), and Britain has a more elaborated 10-point scale from "extremely unhappy to extremely happy" with the two middle categories chosen by around $15 \%$ of the respondents. Formal and informal networks, on the other hand, have different kinds of contents in the measurement devices across the three countries. Though we use the standardized scores of these variables, with theoretically-guided and rigorously-conducted models, it would be preferable to have instruments designed in the same way for cross-societal analysis. To be sure, this study sets up an initial point of comparison for future researchers.

At the theoretical level, our explanation is somewhat speculative. We gave a good deal of effort to describe contextual variations in social structure and relational culture among Australia, Britain, and China, but more effort is needed if we are to produce a more rigorous test of the derived hypotheses. How exactly is the rigidity of class closure to be measured? How is relational culture to be operationalized? What are the behavioral mechanisms whereby the societal variations affect the extent to which formal and informal social networks matter for people's SWB? These questions need to be addressed by a more effective study design. In such a design, there is also an analytical task to be performed about how individual-society interactions alter the effects of informal and, especially, formal social networks on people's SWB and how macro-level factors (such as welfare schemes and health-care policies) are combined with meso-level (such as community cohesion) and micro-level characteristics to jointly affect people's SWB both in a given society and across societies. Such an analysis would not only enhance our understanding of SWB but also disclose important 
features on the similarities and the differences about the social structures in different societies. 


\section{References}

Anderson, R. E. (2014). Human suffering and quality of life: Conceptualizing stories and statistics. New York: Springer.

Baum, F. E., Bush, R. A., Modra, C. C., Murray,C. J., Cox, E. M., Alexander, K. M., \& Potter, R. C. (2000). Epidemiology of participation: An Australian community study. Journal of Epidemiology \& Community Health, 54, 414-423.

Baumeister, R. F. \& Leary, M. R. (1995). The need to belong: Desire for interpersonal attachments as a fundamental human motivation. Psychological Bulletin, 117, 497529.

Berry, H. L., \& Welsh, J. A. (2010). Social capital and health in Australia: An overview from the household, income and labour dynamics in Australia survey. Social Science \& Medicine, 70, 588-596.

Bian, Y. (1994). Guanxi and the allocation of urban jobs in China. China Quarterly, $140,971-999$

Bian, Y. (1997). Bringing strong ties back in: Indirect ties, network bridges, and job searches in China. American Sociological Review, 62, 266-285.

Bian, Y. (2001). Guanxi capital and social eating in Chinese cities: Theoretical models and empirical analyses. In N. Lin, K. S. Cook, \& R. S. Burt (eds), Social capital: Theory and research (pp. 275-296). New York: Aldine de Gruyter..

Bian, Y. (2006). Guanxi. In J. Beckert, \& M. Zafirovski (eds), International encyclopedia of economic sociology (pp. 312-314). New York, NY: Routledge.

Bian, Y. (2010). Relational sociology and its disciplinary status. Social Science Journal 
of Xi'an Jiaotong University, 30, 1-6 (in Chinese).

Bian, Y. 2017. "The Comparative Significance of Guanxi." Management and Organizational Research, 13,161-267.

Bian, Y. In press "The Prevalence and the Increasing Significance of Guanxi." The China Quarterly.

Bian, Y., \& Ang, S. (1997). Guanxi networks and job mobility in China and Singapore. Social Forces, 75, 981-1005.

Bian, Y., \& Hao, M. (2013). Two dimensional social networks and their distributions: A China-Britain comparison. Journal of Sociological Research, 28, 78-97 (in Chinese).

Bian, Y., \& Huang, X. (2015). Beyond the strength of social ties. American Behavioral Scientist, 59, 961-976.

Bian, Y., Huang, X., \& Zhang, L. (2015). Information and favoritism: The network effect on wage income in China. Social Networks, 40, 129-138.

Bian, Y., \& Xiao, Y. (2014). Subjective well-being in China and Britain. Journal of Sociological Research, 29, 22-42 (in Chinese).

Bian, Y., \& Zhang, L. (2014). Corporate social capital in Chinese guanxi culture. Research in the Sociology of Organizations, 40, 417-439.

Bian, Y., Zhang, L., Yang, J., Guo, X., \& Lei, M. (2014). Subjective well-being of Chinese people: A multifaceted view. Social Indicators Research, 121, 75-92.

Bjørnskov, C. (2003). The happy few: Cross-country evidence on social capital and life satisfaction. Kyklos, 56, 3-16. 
Blanden, J., Gregg, P., \& Machin, S. (2005). Intergenerational mobility in Europe and North America. Report supported by the Sutton Trust, Centre for Economic Performance, London School of Economics.

Blau, P., \& Schwartz, J. E. (1984). Crosscutting social circles: Testing a macro structural theory of intergroup elations. New Jersey: Transactions Publishers.

Bourdieu, P. (1986). The forms of capital. In J. G. Richardson (ed.), Handbook of theory and research for the sociology of education (pp. 241-258). New York: Greenwood.

Burt, R.S. (1992). Structural holes: The social structure of competition. Cambridge, MA: Harvard University Press.

Burt, R. S., \& Burzynska, K. (2017). Chinese entrepreneurs, social networks, and guanxi. Management and Organization Review, forthcoming.

Chua, V. (2011). Social networks and labour market outcomes in a meritocracy. Social Networks, 33, 1-11.

Coleman, J. S. (1990). Foundations of social theory. Cambridge, MA: Harvard University Press.

Colman, A.M., Norris, C. E., \& Preston, C. C. (1997). Comparing rating scales of different lengths: Equivalence of scores from 5-point and 7-point scales. Psychological Reports, 80, 355-362.

Devine, F., \& Li, Y. (2013). The changing relationship between origins, education and destinations in the 1990s and 2000s. British Journal of Sociology of Education, 34, 766-791

Dickens, W.T., \& Lang, K. (1988). Labor market segmentation and the union wage 
premium. The Review of Economies and Statistics, 70, 527-530.

Diener, E. (2000). Subjective well-being: The science of happiness and a proposal for a national index. American Psychologist, 55, 34-43.

Diener, E., \& Diener, C. (1995). The wealth of nations revisited: Income and quality of life. Social Indicators Research, 36, 275-286.

DiTomaso, N., \& Bian, Y. (2016). The structure of labor markets in the U.S. and China: Social networks and opportunity hoarding. Paper presented at the annual meeting of the American Sociological Association, Seattle, U.S.

Dolan, P., Peasgood, T., \& White, M. (2008). Do we really know what makes us happy? A review of the economic literature on the factors associated with subjective wellbeing. Journal of Economic Psychology, 29, 94-122.

Durkheim, E. (1951). Suicide: A study in sociology. New York: Free Press.

Easterlin, R. A. (1974). Does economic growth improve the human lot? Some empirical evidence. In P. David \& M. Reder (eds), Nations and Households in Economic Growth (pp. 89-125). New York: Academic Press.

Emmons, R. A., Cheung, C., \& Tehrani, K. (1998). Assessing spirituality through personal goals: Implications for research on religion and subjective well-being. Social Indicators Research, 45, 391-422.

Erikson, R., \& Goldthorpe, J. H. (1992). The constant flux. Oxford: Clarendon Press.

Fei, X. (1992 [1949]). From the soil: The foundations of Chinese society. Berkeley, CA: University of California Press.

Fried, M. H. (1969[1953]). The fabric of Chinese society: A study of the social life of a 
Chinese county seat. New York: Octagon Books.

Gans, H. (1982[1962]). The urban villagers. New York: Free Press.

George, L. K., \& Landerman, R. (1984). Health and subjective well-being: A replicated secondary data analysis. International Journal of Aging and Human Development, 19, 133-156.

Gold, T., Guthrie, D., \& Wank, D. (2004). Social connections in China: Institutions, culture, and the changing nature of guanxi. Cambridge: Cambridge University Press.

Goldthorpe, J. H. \& McKnight, A. (2006).The Economic Basis of Social Class. In S. L. Morgan, D. Grusky and G. S. Fields (eds), Mobility and Inequality: Frontiers of Research in Sociology and Economics (pp. 109-136). California: Stanford University Press.

Goldthorpe, J. H., \& Mills, C. (2008). Trends in intergenerational class mobility in modern Britain: Evidence from national surveys, 1972-2005. National Institute Economic Review, 205, 83-100.

Granovetter, M. S. (1973). The strength of weak ties. American Journal of Sociology, $78,1360-1380$.

Granovetter, M. S. (1985). Economic action and social structure: The problem of embeddedness. American Journal of Sociology, 91, 481-510.

Greenland, S. \& Finkle, W. D. (1995). A critical look at methods for handling missing covariates in epidemiologic regression analyses. American Journal of Epidemiology, $142,1255-1264$.

Hall, E. T. (1959). The Silent Language. New York: Doubleday. 
Hall, P. (1999). Social capital in Britain. British Journal of Political Science, 29, 417461.

Haslam, S. A., Jetten, J., Postmes, T., \& Haslam, C. (2009). Social identity, health, and well-being: An emerging agenda for applied psychology. Applied Psychology, 58, 123.

Heath, A., \& Cheung, S. Y. (2007). The comparative study of ethnic minority disadvantage. In A. Heath and S. Y. Cheung (eds), Unequal chances: Ethnic minorities in western labour markets (pp. 1-44). Oxford: Oxford University Press.

Helliwell, J. F., \& Putnam, R. D. (2004). The social context of well-being. Philosophical Transactions of the Royal Society B Biological Sciences, 359, 14351446.

House, J. S. (2008). Social psychology, social science, and economics: Twentieth century progress and problems, twenty-first century prospects. Social Psychology Quarterly, 71, 232-256.

Huang, X., \& Western, M. (2011).Social networks and occupational attainment in Australia. Sociology, 45, 269-286.

Huang, X., \& Western, M. (2015).Social capital and life satisfaction in Australia. In Y. $\mathrm{Li}$ (ed.), The handbook of research methods and applications on social capital (pp. 225-241). Cheltenham: Edward Elgar Publishing.

Hwang, K. (1987). Face and favor: The Chinese power game. American Journal of Sociology, 92, 944-974.

Jamieson, L. (1998). Intimacy: Personal relationships in modern societies. Cambridge: 
Polity.

Ji, Y. (2013). Social organizations in contemporary China: Theoretical perspectives and empirical research. Journal of Sociological Research, 28, 219-241 (in Chinese).

Jin, J. (2010). Institutionalized official hostility and protest leader logic: A case study of a long-term Chinese peasant collective protest at Dahe Dam. In J. Broadbent \& V. Brockman (eds), East Asian social movements: Power, protest and change in a dynamic region (pp. 413-435). New York: Springer.

King, A. Y. (1985). The individual and group in Confucianism: A relational perspective. In D. J. Munro (ed.), Individualism and Holism: Studies in Confucian and Taoist Values. Center for Chinese Studies, University of Michigan.

King, A. Y. (1991). Kuan-hsi and network building: A sociological interpretation. Daedalus, 120, 63-84.

Kipnis, A. B. (1997). Producing guanxi: Sentiment, self, and subculture in a North China village. Durham, NC: Duke University Press.

Li, Y. (2002). Falling off the ladder? Professional and managerial career trajectories and unemployment experiences. European Sociological Review, 18, 253-270.

Li, Y. (2007). Social capital, social exclusion and well-being. In A. Scriven \& S. Garman (eds), Public health: Social context and action (pp. 60-75). London: Sage.

Li, Y. (2013). Social class and social capital in China and Britain: A comparative study. Social Inclusion, 1, 59-71.

Li, Y. (2015). Social capital in sociological research: conceptual rigour and empirical application. In Y. Li (ed.) The Handbook of Research Methods and Applications on 
Social Capital (pp: 1-20). Cheltenham: Edward Elgar Publishing.

Li, Y. (2016). Social mobility, social network and subjective well-being in the UK. Contemporary Social Research, 11(2-3): 222-237.

Li, Y., \& Devine, F. (2011). Is social mobility really declining? Intergenerational class mobility in Britain in the 1990s and the 2000s. Sociological Research Online, http://www.socresonline.org.uk/16/3/4.html.

Li, Y., \& Devine, F. (2014). Social mobility in Britain, 1991-2011. In L. Archer, A. Mann, \& J. Stanley (eds), Understanding employer engagement in education: Theories and evidence (pp. 79-91). London: Routledge.

Li, Y., \& Heath, A. (2016). Class matters: A study of minority and majority social mobility in Britain, 1982-2011. American Journal of Sociology, 122, 162-200.

Li, Y., Heath, A., \& Devine, F. (2015). Formal and informal social connections in the UK.In Y. Li (ed.), The handbook of research methods and applications on social capital (pp. 187-203). Cheltenham: Edward Elgar Publishing.

Li, Y., \& Marsh, D. (2008). New forms of political participation: Searching for expert citizens and everyday makers. British Journal of Political Science, 38, 247-272.

Li, Y., Pickles, A., \& Savage, M. (2005). Social capital and social trust in Britain. European Sociological Review, 21, 109-123.

Li, Y., Savage, M., \& Pickles, A. (2003). Social capital and social exclusion in England and Wales (1972-1999). British Journal of Sociology, 54, 497-526.

Li, Y., Zhang, S., \& Kong, J. (2015). Social mobility in China and Britain: A comparative study. International Review of Social Research, 5, 20-34. 
Liang, S. (1986 [1949]). The essential meanings of Chinese culture. Hong Kong: Zheng Zhong Press (in Chinese).

Lim, C., \& Putman, R. D. (2010). Religion, social networks, and life satisfaction. American Sociological Review, 75, 914-933.

Lin, N. (1982). Social resources and instrumental action. In P. V. Marsden \& N. Lin (eds), Social structure and network analysis (pp. 131-145). Beverly Hills, CA: Sage.

Lin, N. (2001). Social capital. Cambridge: Cambridge University Press.

Lin, N., Ensel, W. M., \& Vaughn, J. C. (1981). Social resources and strength of ties: Structural factors in occupational status attainment. American Sociological Review, 46, 393-405.

Lindbeck, A., \& Snower, D. J. (1986). Wage setting, unemployment, and insideroutsider relations. American Economic Review, 76, 235-239.

Marsden, P. V., \& Campbell, K. E. (1984). Measuring tie strength. Social Forces, 63, $482-501$

Muttarak, R. (2014). Generation, ethnic and religious diversity in friendship choice: Exploring interethnic close ties in Britain. Ethnic and Racial Studies, 37, 71-98.

Myers. D. G. (2000). The funds, friends, and faith of happy people. American Psychologist, 55, 56-67.

Pahl, R. E. (2000). On friendship. Cambridge: Cambridge: Polity.

Pollner, M. (1989). Divine relations, social relations, and well-being. Journal of Health and Social Behavior, 30, 92-104.

Portes, A. (1998). Social capital: Its origins and applications in modern society. Annual 
Review of Sociology, 24, 1-24.

Putnam, R. D. (1995). Bowling alone: America's declining social capital. The Journal of Democracy, 6, 65-78.

Putnam, R. D. (2000). Bowling alone: The collapse and revival of American community. New York: Simon \& Schuster.

Rabe-Hesketh, S. \& Skrondal, A. (2012). Multilevel and Longitudinal Modelling Using Stata, $3^{\text {rd }}$ Edition, Vols I \& II. College Station, Texas: Stata Press.

Richards, L. (2016). For whom money matters less: Social connectedness as a resilience resource in the UK. Social Indicators Research, 125, 509-535.

Ruan, D., Zhou, L., Blau, P. M., \& Walder, A. G. (1987). An exploratory analysis of urban people's social networks in Tianjin City and comparing with American people. Social Sciences in China, 2, 157-176 (in Chinese).

Song, L. (2011). Social capital and psychological distress. Journal of Health and Social Behavior, 52, 478-492.

Sun, L. (1996). 'Guanxi', social ties and social structure. Journal of Sociological Research, 11, 22-32 (in Chinese).

Thoits, P. A. (2011). Mechanisms linking social ties and support to physical and mental health. Journal of Health and Social Behavior, 52, 145-161.

Walder, A. G. (1986). Communist neo-traditionalism: Work and authority in Chinese industry. Berkeley and Los Angeles: University of California Press.

Western, M. (1991). Class and stratification arrangements for socioeconomic inequality under capitalism. Australian Journal of Political Science, 26, 378-380. 
Western, M. (1994). Intergenerational class mobility among women and men. Australian and New Zealand Journal of Sociology, 30, 303-321.

Whyte, M. K., \& Parish, W. L. (1984).Urban life in contemporary China. University of Chicago Press.

Yan, Y. (1996). The culture of guanxi in a North China village. China Journal, 35, 125.

Yang, M. M. (1994). Gifts, favors, and banquets: The art of social relationships in China. Wilder House, 93, 559-565.

Zhai, X. (2009). Is it 'Guanxi' or social capital? Chinese Journal of Sociology, 29, 109121 (in Chinese).

Zhang, W. (2008).The changing patterns of social networks capital in the process of social transformation. Chinese Journal of Sociology, 3, 73-80 (in Chinese).

Zhao, Y., Li, Y., Heath, A., \&Shryane, N. (2017). Inter- and intra-generational mobility effects on happiness in mainland China. Research in Social Stratification and Mobility, 48, 54-66.

Zheng, X., \& Rabe-Hesketh, S. (2007). Estimating parameters of dichotomous and ordinal item response models with gllamm. The Stata Journal, 7, 313-333. 
Table 1. Distributions of SWB for Original and Adjusted Values by Country

\begin{tabular}{|c|c|c|c|c|c|c|c|c|}
\hline \multirow{2}{*}{$\begin{array}{l}\text { Original } \\
\text { Value }\end{array}$} & \multicolumn{4}{|c|}{ Percent Distribution } & \multicolumn{4}{|c|}{ Adjusted Values } \\
\hline & AUS & BRI & $\mathrm{UCN}$ & $\mathrm{RCN}$ & AUS & BRI & $\mathrm{UCN}$ & $\mathrm{RCN}$ \\
\hline 1 & 1.1 & 0.5 & 1.3 & 1.5 & 1.0 & 0.4 & 0.8 & 0.8 \\
\hline 2 & 9.4 & 0.6 & 6.8 & 8.9 & 2.0 & 0.8 & 1.6 & 1.6 \\
\hline 3 & 58.6 & 1.4 & 44.6 & 45.8 & 3.0 & 1.2 & 2.4 & 2.4 \\
\hline 4 & 31.0 & 2.0 & 40.4 & 39.9 & 4.0 & 1.6 & 3.2 & 3.2 \\
\hline 5 & & 7.4 & 6.9 & 4.0 & & 2.0 & 4.0 & 4.0 \\
\hline 6 & & 7.3 & & & & 2.4 & & \\
\hline 7 & & 18.3 & & & & 2.8 & & \\
\hline 8 & & 28.9 & & & & 3.2 & & \\
\hline 9 & & 16.7 & & & & 3.6 & & \\
\hline \multirow[t]{3}{*}{10} & & 16.9 & & & & 4.0 & & \\
\hline & & & & & Mean(SD & & & \\
\hline & & & & & $3.2(0.6)$ & $3.1(0.7)$ & $2.8(0.6)$ & $2.7(0.6)$ \\
\hline \multirow[t]{4}{*}{$\mathrm{N}$} & 2,238 & 11,493 & 5,330 & 4,366 & \multicolumn{4}{|c|}{ T-test values for country difference } \\
\hline & & & & & AUS & $6.7 * * *$ & $27.3 * * *$ & $30.8 * * *$ \\
\hline & & & & & BRI & & $31.4 * * *$ & $35.9 * * *$ \\
\hline & & & & & UCN & & & $5.5^{* * *}$ \\
\hline
\end{tabular}

Notes:

1. Two-tailed significance: * p. <.05, **p. <.01, ***p. <.001.

2. AUS: Australia; BRI: Britain; UCN: urban China; RCN: rural China (the same in all tables). 
Table 2. Distributions of Networks and Socio-Demographic Attributes

\begin{tabular}{|c|c|c|c|c|}
\hline Variables & $\begin{array}{c}\text { AUS } \\
\mathrm{N}=2,233\end{array}$ & $\begin{array}{c}\text { BRI } \\
\mathrm{N}=8,550\end{array}$ & $\begin{array}{c}\mathrm{UCN} \\
\mathrm{N}=5,330\end{array}$ & $\begin{array}{c}\mathrm{RCN} \\
\mathrm{N}=4,366\end{array}$ \\
\hline \multicolumn{5}{|c|}{ A. Informal networks: contact frequency with relatives and friends } \\
\hline 1 Never & 2.8 & 2.4 & 0.8 & 0.7 \\
\hline 2 Seldom & 34.6 & 12.9 & 3.8 & 4.0 \\
\hline 3 Sometimes & 44.7 & 18.5 & 38.4 & 29.0 \\
\hline 4 Often & 16.1 & 42.0 & 47.2 & 53.6 \\
\hline 5 Very often & 1.9 & 24.2 & 9.8 & 12.7 \\
\hline EAP minimum & -1.1 & -0.4 & -0.5 & -0.5 \\
\hline EAP maximum & 1.1 & 0.2 & 0.3 & 0.3 \\
\hline \multicolumn{5}{|c|}{ B. Formal networks: group memberships and participation } \\
\hline 1 Sports & 42.4 & 22.1 & 39.2 & 5.7 \\
\hline 2 Cultural/Entertainment & 29.1 & 13.7 & 30.6 & 5.7 \\
\hline 3 Religious & 34.3 & 6.3 & 6.7 & 4.3 \\
\hline 4 Community/Social & 39.6 & 6.0 & 32.0 & 6.2 \\
\hline 5 Political/Voluntary & 7.7 & 0.8 & 37.9 & 9.7 \\
\hline EAP minimum & -0.1 & -0.4 & -0.6 & -0.4 \\
\hline EAP maximum & 0.4 & 3.4 & 2.0 & 4.2 \\
\hline \multicolumn{5}{|l|}{ C. Personal Attributes } \\
\hline$\%$ males & 44.0 & 44.9 & 46.9 & 46.8 \\
\hline Age (mean) & 46.0 & 44.4 & 42.7 & 42.6 \\
\hline Health status (mean) & 3.4 & 4.0 & 4.0 & 3.9 \\
\hline$\%$ married & 70.5 & 58.8 & 81.4 & 90.1 \\
\hline$\%$ high school educated & 24.3 & 27.6 & 35.1 & 10.0 \\
\hline$\%$ college educated & 54.1 & 45.1 & 18.2 & 0.4 \\
\hline Annual income (mean) & 44036.1 & 18753.6 & 12341.0 & 4608.9 \\
\hline$\%$ Routine manual & 7.5 & 12.6 & 9.3 & 79.3 \\
\hline$\%$ Skilled-manual & 5.2 & 16.4 & 29.5 & 7.3 \\
\hline$\%$ Supervisor-technician & 12.5 & 19.7 & 28.1 & 10.4 \\
\hline$\%$ Routine non-manual & 38.1 & 17.1 & 15.7 & 1.1 \\
\hline$\%$ Salariat & 36.7 & 34.2 & 17.4 & 1.9 \\
\hline
\end{tabular}

Notes:

1. EAP is the standardized score on people's formal and informal networks.

2. Annual income takes the mid-point of income bands in Australia and Britain. 
Table 3. Average Marginal Effects of Country-Specific Social Networks on SWB

\begin{tabular}{|c|c|c|c|c|}
\hline & AUS & BRI & $\mathrm{UCN}$ & $\mathrm{RCN}$ \\
\hline \multicolumn{5}{|l|}{ Social networks } \\
\hline Informal networks & $0.031 * * *$ & $0.019 * * *$ & $0.042 * * *$ & $0.046 * * *$ \\
\hline Formal networks & 0.004 & $0.008 * *$ & $0.010 * *$ & 0.004 \\
\hline \multicolumn{5}{|l|}{ Control variables } \\
\hline Male & $-0.032 * * *$ & $-0.019 * *$ & $-0.015^{*}$ & $-0.018 * *$ \\
\hline Age/10 & -0.022 & $-0.098 * * *$ & $-0.172 * * *$ & $-0.010 * * *$ \\
\hline$(\text { Age } / 10)^{2}$ & 0.004 & $0.012 * * *$ & $0.019 * * *$ & $0.012 * * *$ \\
\hline Health status & $0.077 * * *$ & $0.067 * * *$ & $0.046^{* * *}$ & $0.043 * * *$ \\
\hline Married & $0.065 * * *$ & $0.097 * * *$ & $0.133 * * *$ & $0.110 * * *$ \\
\hline Higher secondary & -0.002 & $0.017^{*}$ & $0.014 *$ & 0.007 \\
\hline College & -0.009 & -0.001 & $0.032 * * *$ & -0.010 \\
\hline Income (sample Z-score) & 0.007 & $0.018 * * *$ & $0.015 * * *$ & $0.041 * * *$ \\
\hline Skilled-manual & -0.024 & -0.020 & 0.013 & 0.022 \\
\hline Supervisor-technician & -0.030 & -0.021 & 0.011 & 0.007 \\
\hline Routine non-manual & $-0.041 *$ & -0.014 & $0.040 * *$ & -0.039 \\
\hline Salariat & -0.020 & -0.021 & $0.046^{* * *}$ & $0.048 *$ \\
\hline $\mathrm{R}^{2}$ & 0.213 & 0.154 & 0.182 & 0.140 \\
\hline $\mathrm{N}$ & 1,757 & 5,308 & 4,645 & 4,142 \\
\hline
\end{tabular}

Notes:

1. Reference groups in the control variables are female, lower secondary education or below, non-married, and routine manual workers.

2. $\mathrm{p}<0.05, * * \mathrm{p}<0.01, * * * \mathrm{p}<0.001$. 
Table 4. Average Marginal Effects of Cross-Society Social Networks on SWB

\begin{tabular}{lccc}
\hline & Base model & $\begin{array}{l}\text { Main interaction } \\
\text { model }\end{array}$ & $\begin{array}{l}\text { Full } \\
\text { interaction } \\
\text { model }\end{array}$ \\
\hline Society (base=rural China) & & & \\
$\quad$ Australia & $.172^{* * *}$ & $.173^{* * *}$ & -.036 \\
Britain & $.145^{* * *}$ & $.145^{* * *}$ & .062 \\
Urban China & $.023^{* * *}$ & $.023^{* * *}$ & $.123^{*}$ \\
Informal networks*society & $.038^{* * *}$ & $.050^{* * *}$ & $.043^{* * *}$ \\
$\quad$ x Australia & & $-.019^{* *}$ & -.009 \\
$\quad$ x Britain & & $-.033^{* * *}$ & $-.022^{* * *}$ \\
$\quad$ x Urban China & & -.001 & -.003 \\
Formal networks*society & $.015^{* * *}$ & $.010^{* * *}$ & .004 \\
$\quad$ x Australia & & .002 & .001 \\
$\quad$ x Britain & & $.008^{*}$ & .005 \\
x Urban China & & $.011^{* *}$ & .005 \\
$\mathrm{R}^{2}$ & & & 0.243 \\
$\mathrm{~N}$ & 0.126 & 0.130 & 15,852 \\
\hline
\end{tabular}

Notes:

1. $\mathrm{p}<0.05, * * \mathrm{p}<0.01, * * * \mathrm{p}<0.001$.

2. The coefficients for the control variables (as used in Table 3) are not presented but are available upon request. 